\title{
Specific expression of a novel cell wall hydroxyproline-rich glycoprotein gene in lateral root initiation
}

\author{
Beat Keller' ${ }^{1}$ and Christopher J. Lamb ${ }^{2}$ \\ Plant Biology Laboratory, Salk Institute for Biological Studies, La Jolla, California 92037 USA
}

\begin{abstract}
A gene encoding a novel cell wall hydroxyproline-rich glycoprotein (HRGPnt3) was isolated from a genomic library of tobacco. The deduced protein $\left(620\right.$ amino acids, $\left.M_{\mathrm{r}} 65,406\right)$ contains an amino-terminal hydrophobic signal peptide, is highly basic, and is rich in proline, although characteristic Ser-Pro ${ }_{4}$ repeats are found only beyond residue 204. At the carboxyl terminus, there is a 34-amino-acid unit repeated three times. Arginine is the predominant basic amino acid rather than lysine, as in other HRGPs. A second gene homologous to HRGPnt3 was revealed by Southern blot hybridization of tobacco genomic DNA. Northern blot hybridization identified a 1.9-kb transcript present at low levels in roots. To determine the underlying spatial pattern of expression, the HRGPnt3 promoter and the first 27 nucleotides of the open reading frame were fused to the $\beta$ glucuronidase (GUS) reporter gene and transformed back into tobacco. Histochemical localization of GUS activity showed that the HRGPnt 3 promoter was transiently induced in the pericycle and endodermis, specifically in the discrete, small subset of cells involved in the initiation of lateral roots. This pattern of expression, in cells destined to form the tip of the emerging lateral root, indicates that the encoded cell wall protein has a specialized structural function, possibly in the mechanical penetration of the cortex and epidermis of the main root, and that the HRGPnt 3 promoter responds to an early morphogenetic signal for lateral root induction.
\end{abstract}

[Key Words: Cell wall; hydroxyproline-rich glycoprotein; lateral roots; morphogenesis; transgenic plants]

Received July 20, 1989; revised version accepted August 21, 1989.

In contrast to the cells of other higher eukaryotes, plant cells are surrounded by cell walls. These walls are responsible for cellular adhesion in plant tissues and collectively give shape and stability to the whole plant. The presence of the cell wall precludes the extensive cell migration observed during animal embryogenesis, and, with a few notable exceptions such as the penetration of lateral roots through the cortex and epidermis of the main root, neighboring plant cells remain in fixed juxtaposition to one another during development. Thus, the final form of a plant organ and, ultimately, the plant itself is determined by the three-dimensional deposition of cell wall components during cell division, subsequent expansion growth, and cellular maturation.

During cellular development, the architecture of the cell wall changes in an orderly manner, reflecting changes in the proportions of various structural polysaccharides, including cellulose and components of the complex matrix of pectin and hemicellulose polymers in which the cellulose microfibrils are embedded (Lamb 1981). Moreover, the wall of a differentiating plant cell is specifically adapted to the particular function of that cell type (Varner and Lin 1989). This results in qualita-

${ }^{1}$ Present address: Swiss Federal Research Station for Agronomy, CH-8046 Zürich, Switzerland.

${ }^{2}$ Corresponding author. tive and quantitative differences in the cell wall composition of different cell types. For example, epidermal cells become impregnated with the aliphatic polymer cutin to prevent water loss. Likewise, the cell walls of xylem tracheary elements have secondary thickenings laid down on the primary cell wall, and these later become lignified to provide the mechanical strength needed for water translocation.

These specific wall adaptations clearly distinguish the different cell types. Genes involved in these adaptations must be regulated specifically and therefore represent good systems for studying cellular differentiation in plants. Recent data show that a gene encoding phenylalanine ammonia-lyase, which catalyzes the first step in the synthesis of lignin monomers, is specifically activated at an early stage of vascular development at the inception of xylem differentiation (Bevan et al. 1989; Liang et al. 1989). However, with this exception, little information is currently available on the genetic control mechanisms governing the synthesis of cell wall polysaccharides, lignin, cutin, and other nonproteinaceous cell wall polymers.

In addition, plant cell walls also contain structural proteins. Two major classes of structural proteins have been described to date: hydroxyproline-rich glycoproteins (HRGPs; for review, see Cassab and Varner 1988) and glycine-rich proteins (GRPs). Emerging data indicate 
that, as observed previously for other cell wall polymers, the deposition of specific HRGPs and GRPs is restricted to particular tissues or cell types. Thus, a bean GRP containing $\sim 60 \%$ glycine arranged in a very regular primary structure is closely associated with the vascular system (Keller et al. 1988). In more detailed studies, it was shown that this GRP is localized exclusively in the lignified secondary thickenings of the cell wall tracheary elements of the protoxylem (Keller et al. 1989b). The highly localized deposition indicates that this GRP has a specific function in the cell wall of young, elongating tracheary elements. Analysis of transgenic plants containing a GRP promoter- $\beta$-glucuronidase (GUS) reporter gene fusion showed that this pattern is established by cell-type-specific transcription of the GRP gene (Keller et al. 1989a).

HRGPs or extensins have been found in many plants (Lamport 1970) and contain a characteristic repeat of the pentapeptide Ser-Pro ${ }_{4}$ (Cassab and Varner 1988). The proline residue is hydroxylated and then glycosylated. HRGPs gradually become insolubilized, probably by the formation of covalent linkages to other HRGPs or nonproteinaceous components of the cell wall (Fry 1986), thereby mechanically strengthening the wall. A soybean HRGP was shown to be localized in sclerenchyma tissue of the seed coat in soybean and in the vascular tissue of cotyledons (Cassab and Varner 1987), consistent with a putative function in structural reinforcement of the walls of specific cell types.

Here we describe the cell-type-specific expression of a novel HRGP gene in tobacco. The encoded protein has two clearly distinct domains and is structurally different from other HRGPs. We show that the gene is strongly but transiently expressed in roots, specifically in the subset of cells in the endodermis and pericycle involved in the initiation of lateral root development. This unique pattern of expression in cells destined to form the tip of the new root suggests a correspondingly specific function for this particular HRGP in the reinforcement of the wall to enable these cells to withstand the mechanical pressure involved in breaking through the surrounding tissues of the main root. These data, together with the parallel study of GRP gene expression, suggest that plant development involves an exquisitely precise morphogenetic control of cell wall architecture mediated by the selective transcription of genes encoding specific structural proteins.

\section{Results}

\section{Isolation and structure of HRGPnt3}

The genomic clone HRGPnt 3 , encoding a tobacco HRGP, was isolated by screening a tobacco genomic library constructed in the vector $\lambda E M B L 4$, using the bean HRGP cDNA Hyp 2.11 (Sauer et al. 1989) as a probe. A map of HRGPnt3 is shown in Figure 1. The EcoRI fragments were cloned separately and then aligned by comparing their restriction pattern with that of the intact $\lambda$ phage.

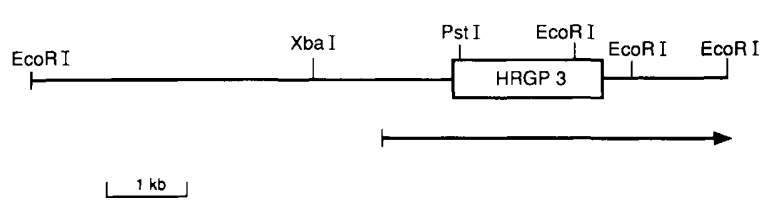

Figure 1. Restriction map of the genomic clone $\lambda H R G P n t 3$ of tobacco. The coding region is represented by a box, and some restriction sites are given. The arrow indicates the region that was sequenced; part of this sequence is shown in Fig. 2. The complete sequence data will appear in the EMBL/GenBank/ DPBJ nucleotide sequence data bases under the accession number X13885.

Nucleotide sequence analysis showed that the HRGPnt3 gene contains a single long open reading frame (ORF) that codes for a protein of 620 amino acids. The nucleotide sequence and the derived amino acid sequence are shown in Figure 2. The encoded protein, $M_{r}$ 65,406, contains many Ser-Pro ${ }_{4}$ repeats characteristic of the primary translation products of cell wall HRGPs (Cassab and Varner 1988) and has a hydrophobic aminoterminal sequence, which resembles signal sequences of various secreted proteins in eukaryotes (von Heijne 1988 .

The protein contains $43 \%$ proline, $12 \%$ serine and, moreover, is rich in tyrosine $(6 \%)$ and histidine $(5 \%)$, which are putatively involved in intermolecular crosslinking of HRGPs in the cell wall (Fry 1986; Cassab and Varner 1988|. HRGPnt3 is a highly basic protein, with 26 positive charges and only 2 negative charges, excluding the amino and carboxyl termini. Interestingly, 25 of the basic amino acid residues are arginine, and there is only 1 lysine. In other cell wall HRGPs described to date, the predominant basic amino acid is lysine (Cassab and Varner 1988). Table 1 shows the amino acid composition of HRGPnt3, deduced from the sequence in Figure 2.

Although the entire HRGPnt3 protein beyond the putative signal peptide is proline rich, Ser-Pro ${ }_{4}$ units are only found in the carboxy-terminal domain starting at amino acid 205. The Ser-Pro ${ }_{4}$ units are usually preceded by the sequence Thr-Lys. Within this domain, adjacent to the carboxyl terminus, there is a sequence of 34 amino acids repeated almost perfectly three times, with a maximum of four differences from the consensus repeat sequence. Of the 34 amino acid residues in the repeat, 15 or 16 are proline. The structure of the repeat is shown in Figure 3 . In addition, the sequence His-AlaPro-Pro is repeated four times /residues 70-73, $148-151,232-235$, and 239-242), with the last two embedded in a tandem repeat of the sequence Thr-HisArg-His-Ala-Pro-Pro. Arginine, histidine, and lysine are found only in the amino-terminal region before residue 258 and in the three long carboxy-terminal repeats beyond residue 499 . Thus, within the region containing Ser-Pro ${ }_{4}$ repeats there is a stretch of $\sim 240$ residues without any basic amino acids, which is very unusual for an HRGP (Cassab and Varner 1988).

The HRGPnt3 gene has a potential TATA box $\sim 50 \mathrm{bp}$ 


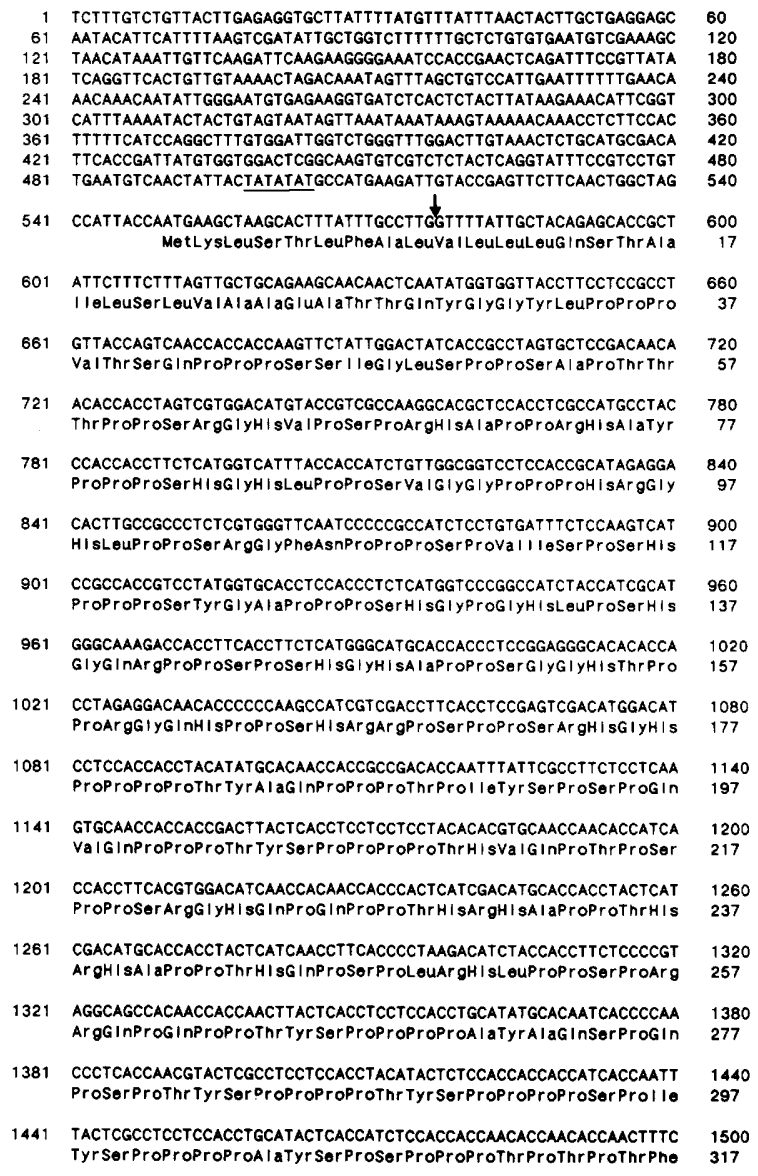

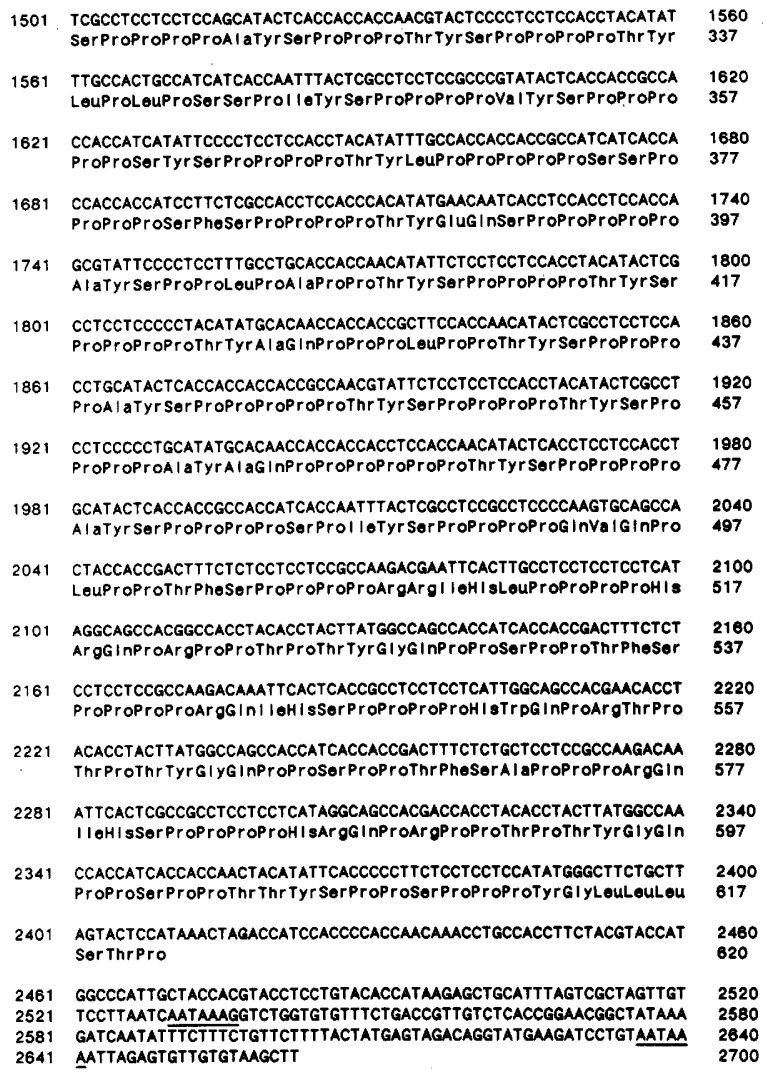

,

Figure 2. Nucleotide and derived amino acid sequence of HRGPnt3. Nucleotides are numbered on both sides; amino acids are numbered only on the right. The TATA box and the putative polyadenylation signals are underlined. The arrow marks the position of the translational fusion between the HRGPnt3 gene and the GUS reporter gene, which was used for plant transformation.

upstream of the ATG start codon. There is an AATAAA sequence as a putative polyadenylation site $120 \mathrm{bp}$ after the stop codon. If these signals are used in transcription, the transcript would be expected to be $\sim 2.0 \mathrm{~kb}$ long.

\section{HRGPnt3-related sequences}

To compare the complexity of HRGP-related sequences in the bean and tobacco genomes, we hybridized Southern blots of genomic DNA with the bean HRGP 2.11 cDNA sequence. Under low stringency conditions, many more fragments hybridized in genomic DNA from bean than from tobacco (Fig. 4a), suggesting that bean contains more HRGP-related sequences, although some of these signals may represent cross hybridization with GRP sequences (Keller et al. 1988), which also contain GC-rich coding regions (glycine codons, GGN; proline codons, CCN). When sequences of the isolated tobacco HRGPnt3 gene were used to probe a Southern blot of tobacco genomic DNA, two bands of $\sim 8.2$ and $7.2 \mathrm{~kb}$ hybridized under high stringency conditions (Fig. 4b). The latter probably corresponds to the isolated HRGPnt3 gene, because this gene is located on a $6.9-\mathrm{kb}$ EcoRI fragment in the $\lambda$ clone. The 8.2 -kb fragment may contain a second gene highly related to HRGPnt3.

\section{HRGPnt3 transcripts}

HRGPnt3 gene sequences hybridized specifically to a single transcript present at low levels in total cellular RNA extracted from tobacco roots. The transcript runs just below the 18S RNA and, thus, has a size of $\sim 1.9 \mathrm{~kb}$, in close agreement with the transcript size deduced from nucleotide sequencing of the HRGPnt3 gene (see above). There was no detectable hybridization with total cellular RNA isolated from mature stems or leaves, and the transcript was not induced by excision-wounding (data not shown). No other plant organs were analyzed for the presence of HRGPnt3 RNA.

\section{Localization of HRGPnt3 expression}

The low abundance of the HRGPnt 3 transcript contrasts with the marked accumulation of the transcripts of other HRGP genes (Corbin et al. 1987; Chen and Varner 1985; Showalter et al. 1985) and suggests that expression of the HRGPnt3 gene might be restricted to a specific cell type or tissue. To investigate the underlying spatial pattern of expression of the HRGPnt3 gene, the 5'flanking region and first 27 nucleotides of the ORF were fused to the GUS reporter gene (Jefferson et al. 1987) to 
Table 1. Amino acid composition of the tobacco HRGPnt3 protein

\begin{tabular}{lc}
\hline Residue & Number \\
\hline Ala & 25 \\
Cys & 0 \\
Asp & 0 \\
Glu & 2 \\
Phe & 7 \\
Gly & 23 \\
His & 32 \\
Ile & 10 \\
Lys & 1 \\
Leu & 25 \\
Met & 1 \\
Asn & 1 \\
Pro & 266 \\
Gln & 29 \\
Arg & 25 \\
Ser & 77 \\
Thr & 47 \\
Val & 10 \\
Trp & 1 \\
Tyr & 38 \\
\hline
\end{tabular}

aAmino acid composition derived from the nucleotide sequence shown in Fig. 2.

give a translational fusion (see Fig. 1). Following Agrobacterium-mediated leaf disc transformation of tobacco with this construct, the expression of the gene fusion was studied in the homologous system. Six kanamycinresistant transformants were first analyzed for GUS activity by a fluorimetric assay in extracts of roots, leaves, and stems. Expression above background levels was detected in only two plants. In root extracts, the expression was about fivefold over background and about twofold in stem extracts, the latter activity possibly arising from the frequent initiation of aerial roots in tobacco plantlets grown in magenta jars.

The spatial distribution of GUS activity in these plants was determined histochemically by an in situ assay using the colorigenic substrate X-gluc (Jefferson et al. 1987). No histochemical staining was observed in stems, leaves, flowers, or developing seeds. Only very few cells were stained in roots of axenically grown plants; however, these cells strongly express the gene. Closer inspection showed that these cells are all located where lateral roots are being initiated. Figure 5 gives several examples of such developing lateral roots. Figure 5,

\section{PPPTYSPPPPAYAQPPPPPPTYSPPPPAYSPPPPSPIYSPPPPQVQPL}

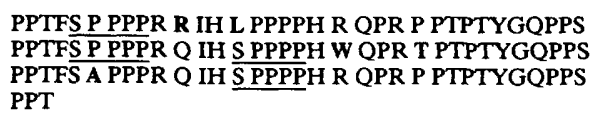

\section{TYSPPSPPPYGLLLSTP*}

Figure 3. Carboxy-terminal repeated sequences of HRGPnt3. The last 170 amino acids of the protein are arranged to show the 34 amino acids that are repeated three times. Embedded in the long repeat are some pentapeptide sequences $\mathrm{SP}_{4}$ /underlined). The sequence shown starts at amino acid 451 .

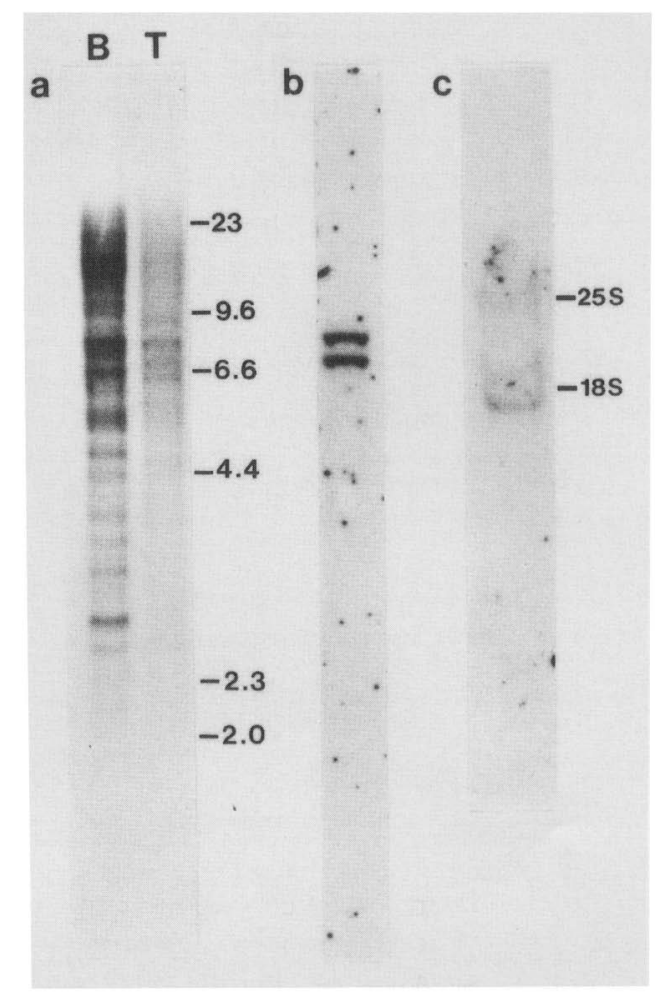

Figure 4. Southern and Northern blot hybridization analysis of HRGP sequences. (a) Southern blot of genomic DNA from young leaves of bean (B) and tobacco $(T)$. EcoRI fragments were separated on a $0.7 \%$ agarose gel, blotted onto nitrocellulose, hybridized to ${ }^{32}$ P-labeled sequences of the bean HRGP2.11 cDNA, and washed under low stringency conditions. (b) Southern blot of EcoRI-digested tobacco DNA probed with the PstI-EcoRI fragment of the tobacco HRGPnt3-coding region and washed under high-stringency conditions. (c) Northern blot of total cellular RNA $(10 \mu \mathrm{g})$ isolated from axenically grown tobacco roots and hybridized with the PstI-EcoRI HRGPnt 3 probe. The positions of rRNAs (18S and 25S) are indicated.

$a$ and $b$, shows a very early stage of lateral root initiation where a subset of pericycle and endodermal cells have started to divide. Strong GUS activity is observed specifically in these cells. Figure 5, c and d, shows later stages of lateral root development when the new root is mechanically breaking through the cortex of the parental root. At this stage, only cells in the apical part of the developing lateral root are stained. There is a strikingly sharp separation between cells displaying high levels of GUS activity and cells having no visible reaction. At an even later stage (Fig. 5e,f), GUS activity is still restricted to the tip of the emerging lateral root, but the staining is very weak, indicating that there is a transient induction of the gene fusion followed by slow decay of residual GUS activity. In lateral roots longer than the one shown in Figure 5f, no histochemical staining was observed in the root tip. The tip of the main root did not express the HRGPnt3-GUS gene either. No expression of the HRGPnt3-GUS gene fusion was detected in other parts of the lateral root or in adjacent tissues of the main root. 
Production of the histochemical stain involves oxidative dimerization of the immediate enzymatic product of the GUS reaction with $\beta$-glucuronide (X-Gluc) (Jefferson 1987). However, the same specific pattern was obtained when the staining reaction was performed in the presence of an exogenous oxidation catalyst (Jefferson 1987), indicating that this pattern does not reflect localized high levels of peroxidase or other endogenous oxidative enzyme. Moreover, this characteristic staining pattern was not observed in untransformed plants or plants transformed with other gene fusions, the promoterless GUS plasmid pBI101.1, or constructs lacking the GUS gene (Fig. 5g). Thus, we conclude that the distinctive pattern of GUS activity in transgenic tobacco plants containing the HRGPnt3-GUS gene fusion is established by the specific properties of the HRGPnt3 promoter, which is strongly but transiently activated at the onset of lateral root formation in those cells destined to form the tip of the emerging new root.

\section{Discussion}

We isolated a gene encoding a novel HRGP, which exhibits a unique and very specific developmental pattern of expression. The encoded protein is most likely secreted to the cell wall, as it has a hydrophobic amino-terminal signal sequence. A distinctive feature of HRGPnt3, compared with other cell wall HRGPs, is the high arginine content with an almost complete absence of lysine. Other cell wall HRGPs examined to date are also highly basic but are rich in lysine, not arginine (Chen and Varner 1985; Corbin et al. 1987; Cassab and Varner 1988). The 34-amino-acid carboxy-terminal sequence that is repeated three times represents another distinctive feature of this protein. Some other repetitive sequences have been reported in stress-induced bean HRGPs (Corbin et al. 1987), where a tyrosine-rich 16mer sequence containing two Ser-Pro ${ }_{4}$ units is repeated many times. Interestingly, in at least one of these genes, the repeats are also clustered at the carboxyl terminus.

The HRGPnt3 gene was found to be expressed weakly in roots, both by hybridization to Northern blots and by fluorimetric assay of GUS activity in extracts of transgenic plants containing the HRGPnt3-GUS gene fusion. However, analysis of the spatial pattern of GUS activity by a nonaveraging in situ assay showed that this reflects highly localized expression in a very small number of cells. Thus, the pattern of GUS activity revealed a strong but transient expression of the HRGPnt3-GUS gene fusion in the endodermis and pericycle, specifically in those cells involved in the initiation of lateral root development, although we cannot rule out very weak expression in other cells at a level below that required to produce a visible stain in the histochemical analysis.

Several hundred base pairs of the immediate $5^{\prime}$ flanking regions of plant genes generally appear to be sufficient to confer the appropriate pattern of expression on heterologous reporter genes (Willmitzer 1988). Recent data indicate that this holds true in terms of cell and tissue specificity, as monitored by the spatial pattern of GUS activity in transgenic plants containing, for example, glycine-rich protein-, patatin-, or phenylalanine ammonia-lyase-GUS gene fusions (Bevan et al. 1989; Keller et al. 1989a; Rocha-Sosa et al. 1989; Liang et al. 1989|. Moreover, in tissue prints of cucumber seedlings, the sites of lateral root development show strong immunoreactivity with a polyclonal antibody to a soybean cell wall HRGP (Song Yan-ru and J.E. Varner, pers. comm.). Therefore, the pattern of expression that we observed with the HRGPnt3-GUS gene fusion is very likely to reflect that of the endogenous HRGPnt3 gene.

The highly cell-type-specific expression of HRGPnt3 during lateral root initiation suggests a correspondingly specific function for this cell wall protein. Because lateral roots originate from the endodermis and pericycle, which surround the vascular cylinder, the new roots have to break through the cortex and the epidermis of the parental root. The cells at the tip of a lateral root must encounter strong mechanical pressure during this developmental process. Deposition of HRGPnt3 may reinforce walls in cells at the tip of the new root to withstand these mechanical forces, and this putative function would fully explain the early but transient expression of the HRGPnt3 gene specifically in these cells. Possibly, the main root tip is also strengthened by deposition of HRGPnt3 protein very early in development. Early deposition of stable wall protein in main and lateral root tips might enforce cell walls for a long time, and continuous deposition would be unnecessary.

Although HRGPnt3 expression is restricted to those cells destined to form the tip of the lateral root, reactivity with the HRGP antibody is not only observed in the lateral root, but also in adjacent tissue of the main root (S. Yan-ru and J.E. Varner, pers. comm.). The HRGPnt3 gene is not induced by wounding, consistent with the lack of induction of this specific HRGP gene in the cortex of the main root during penetration by the lateral root. Hence, other HRGP genes, inducible by wounding (Chen and Varner 1985; Corbin et al. 1987),

Figure 5. (See p. 1644 for figure.) Histochemical localization of GUS activity in transgenic tobacco plants. $(a-f)$ Sequential stages of the initiation and development of lateral roots in tobacco plants carrying the GUS reporter gene under the control of the HRGPnt3 promoter. $(a)$ The endodermis can be distinguished clearly. $(g)$ Lateral root in a control plant transformed with the promoterless GUS plasmid pBI101.3. Bars, $100 \mu \mathrm{m}$. 


\section{Keller and Lamb}
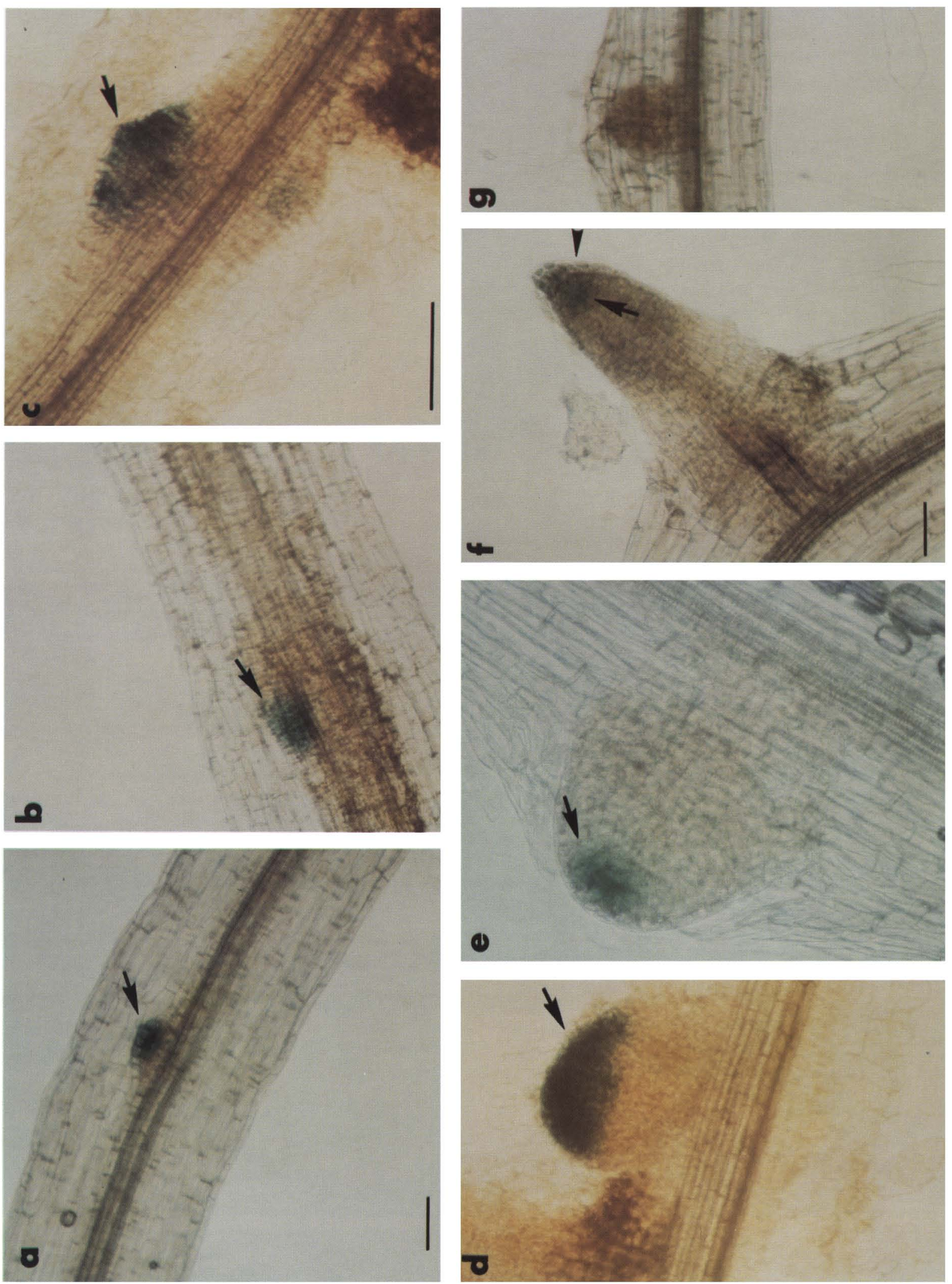

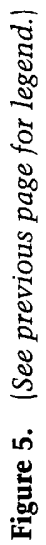




may subsequently be activated in the main root as part of a repair mechanism following damage to the cortex caused by the lateral root breaking through.

Nodule formation in legumes is also a process of new growth at specific internal sites in the root. Interestingly, a proline-rich protein (nodulin-75) was found to be expressed specifically at early stages of nodule morphogenesis (Franssen et al. 1987). Although this protein contains repeats of the motif Pro-Pro-His-Glu-Lys-Pro-Pro, rather than Ser-Pro ${ }_{4}$ repeats, it may have a similar role during nodule formation as that proposed here for HRGPnt 3 during lateral root initiation. Thus, reinforcement of cell walls by the deposition of proline-rich proteins may be a general requirement for penetration of the root cortex by a newly formed meristem.

The specific transient induction of the HRGPnt 3 gene in a subset of endodermis and pericycle cells at the inception of lateral root development represents a novel pattern of plant gene expression. The formation of a new lateral root is a key event during plant development, and HRGPnt3 induction appears to be one of the earliest differentiation events following initiation of cell division. Exogenous auxin stimulates lateral root initiation (Blakely et al. 1988); hence, it will be of interest to examine the regulation of the HRGPnt 3 gene by auxin and other potential morphogenetic signals. Dissection of the mechanisms underlying HRGPnt3 expression at the onset of lateral root formation should give an insight into the molecular basis of this key morphogenetic event.

Cell-type-specific expression has now been reported for several plant cell wall structural proteins: a carrot cell wall HRGP found mainly in sclerenchyma tissue (Cassab and Varner 1987), a GRP of bean in protoxylem tracheary elements (Keller et al. 1989b), and now HRGPnt 3 in a small set of cells in newly formed lateral roots. We propose that selective activation of genes encoding specific structural proteins provides a mechanism for precise morphogenetic control of cell wall architecture during cellular differentiation. Use of gene transfer techniques to introduce genes encoding modified versions of these cell wall proteins or to alter celltype-specific patterns of expression should provide new approaches to the study of the developmental control of plant cell wall structure and function.

\section{Materials and methods}

\section{DNA and RNA isolation}

Genomic DNA was isolated from young leaves of axenically grown tobacco plants (Nicotiana tabacum cv. Xanthi), as described by Murray and Thompson (1980). Total cellular RNA was isolated, as described previously (Bell et al. 1986).

\section{Genomic library construction and screening}

Tobacco genomic DNA was partially digested with Sau3A, and fragments of an average length of $15 \mathrm{~kb}$ were ligated into $\lambda E M B L 4$ (Frischauf et al. 1983). The genomic library was then screened for HRCP genes using the bean cDNA Hyp 2.11 (Sauer et al. 1989) as a probe.

\section{Nucleic acid hybridization and DNA sequencing}

Hybridization of probes to plaques of the genomic library was performed at $37^{\circ} \mathrm{C}$ in $30 \%$ formamide, $5 \times \mathrm{SSC}(1 \times \mathrm{SSC}$ is 0.15 $\mathrm{M} \mathrm{NaCl}, 0.015 \mathrm{M}$ sodium citrate, $0.1 \%$ SDS, $100 \mu \mathrm{g} / \mathrm{ml}$ of denatured single-stranded salmon sperm DNA, and $1 \times$ Denhardt's solution. These conditions were also used for the Southern blot hybridization performed under low stringency (Fig. 4a). Homologous hybridizations of a nick-translated (Rigby et al. 1977) HRGPnt3 probe to Southern and Northern blots were performed at $42^{\circ} \mathrm{C}$ in $50 \%$ formamide, $2 \times$ SSC, $0.1 \%$ SDS, and 100 $\mu \mathrm{g} / \mathrm{ml}$ salmon sperm DNA. Final washes for hybridization of the bean cDNA probe to the genomic library and the low stringency Southern blot were at $37^{\circ} \mathrm{C}$ in $0.3 \times$ SSC, $0.1 \%$ SDS. Final washes of high stringency Northern and Southern blots were performed in $0.1 \times \mathrm{SSC}, 0.1 \%$ SDS, at $55^{\circ} \mathrm{C}$ and $65^{\circ} \mathrm{C}$, respectively.

DNA sequences were determined by the chemical degradation method (Maxam and Gilbert 1980) after deletions were obtained using Bal31 nuclease. The complete sequence data will appear in the EMBL/GenBank/DPBJ nucleotide sequence data banks under the accession number X13885.

\section{Gel electrophoresis}

RNA was separated on formaldehyde denaturing gels in $1 \%$ agarose (Maniatis et al. 1982).

\section{HRGPnt3 promoter-GUS fusion, plant transformation, and analysis}

An $X b a$ I-StyI fragment of $\sim 1.3 \mathrm{~kb}$ promoter sequence, which contains the first $27 \mathrm{bp}$ of the HRGPnt3-coding region (see Fig. 2 ), was cloned into $X$ baI-SmaI-cut pBI 101.3 vector (Jefferson et al. 1987), after the StyI site was filled in with Klenow polymerase. The resulting fusion was verified by nucleotide sequence analysis using a GUS-specific primer /Clontech, Palo Alto, California). Then the plasmid was mobilized into Agrobacterium tumefaciens LBA 4404, as described by Bevan (1984). Leaf discs of $N$. tabacum cv. Xanthi were transformed as described by Horsch et al. (1984), and transformants were selected on $200 \mu \mathrm{g} / \mathrm{ml}$ kanamycin and $500 \mu \mathrm{g} / \mathrm{ml}$ carbenicillin or cefotaxim.

\section{Acknowledgments}

We thank Song Yan-ru and J.E. Varner for communicating unpublished data, Susan A. Hedrick for assistance in construction of the genomic library, Jürg Schmid for some control tobacco plants, and Cindy Doane for preparation of the manuscript. This work was supported by grants from the Samuel Roberts Noble Foundation and CIBA-GEIGY to C.J.L. B.K. was the recipient of a postdoctoral fellowship from the European Molecular Biology Organisation.

\section{References}

Bell, J.N., T.B. Ryder, V.P.M. Wingate, J.A. Bailey, and C.J. Lamb. 1986. Differential accumulation of plant defense gene transcripts in a compatible and incompatible plant-pathogen interaction. Mol. Cell Biol. 6: 1615-1623.

Bevan, M. 1984. Binary Agrobacterium vectors for plant transformation. Nucleic Acids Res. 12: 8711-8721.

Bevan, M., D. Shufflebottom, K. Edwards, R. Jefferson, and W. Schuch. 1989. Cell- and tissue-specific expression of a phe- 
nylalanine ammonia-lyase promoter in transgenic plants. $E M B O$ \%. 8: 1899-1906.

Blakely, L.M., R.M. Blakely, P.M. Colowit, and D.S. Elliott. 1988. Experimental studies on lateral root formation in radish seedling roots. II. Analysis of the dose-response to exogenous auxin. Plant Physiol. 87: 414-419.

Cassab, G.I. and J.E. Varner. 1987. Immunocytolocalization of extensin in developing soybean seed coats by immunogoldsilver staining and by tissue printing on nitrocellulose paper. J. Cell Biol. 105: 2581-2588.

- 1988. Cell wall proteins. Annu. Rev. Plant Physiol. Plant Mol. Biol. 39: 321-353.

Chen, J. and J.E. Varner. 1985. An extracellular matrix protein in plants: Characterization of a genomic clone for carrot extensin. EMBO I. 4: 2145-2151.

Corbin, D.R., N. Sauer, and C.J. Lamb. 1987. Differential regulation of a hydroxyproline-rich glycoprotein gene family in wounded and infected plants. Mol. Cell. Biol. 7: 4337-4344.

Franssen, H.J., J.-P. Nap, T. Gloudemans, W. Stiekema, H. Van Dam, F. Govers, J. Louwerse, A. Van Kammen, and T. Bisseling. 1987. Characterization of cDNA for nodulin-75 of soybean: A gene product involved in early stages of root nodule development. Proc. Natl. Acad. Sci. 84: 4495-4499.

Frischauf, A.-M., H. Lehrach, A. Poustka, and N. Murray. 1983. Lambda replacement vectors carrying polylinker sequences. J. Mol. Biol. 170: 827-842.

Fry, S.C. 1986. Cross-linking of matrix polymers in growing cell walls of angiosperms. Annu. Rev. Plant Physiol. 37: 165186.

Horsch, R.B., R.T. Fraley, S.G. Rogers, P.R. Sanders, A. Lloyd, and N. Hoffmann. 1984. Inheritance of functional foreign genes in plants. Science 223: 496-498.

Jefferson, R.A. 1987. Assaying chimeric genes in plants: The GUS gene fusion system. Plant Mol. Biol. Reporter 5: $387-$ 405.

Jefferson, R.A., T.A. Kavanagh, and M.W. Bevan. 1987. GUS fusions: $\beta$-Glucuronidase as a sensitive and versatile gene fusion marker in higher plants. EMBO I. 6: 3901-3907.

Keller, B., N. Sauer, and C.J. Lamb. 1988. Glycine-rich cell wall proteins in bean: Gene structure and association of the protein with the vascular system. EMBO I. 7:3625-3633.

Keller, B., J. Schmid, and C.J. Lamb. 1989a. Vascular expression of a bean cell wall glycine-rich protein- $\beta$-glucuronidase gene fusion in transgenic tobacco. $E M B O /$. 8: 1309-1314.

Keller, B., M.D. Templeton, and C.J. Lamb. 1989b. Specific localization of a plant cell wall glycine-rich protein in protoxylem cells of the vascular system. Proc. Natl. Acad. Sci. 86: $1529-1533$.

Lamb, C.J. 1981. Molecular approaches to the study of cell differentiation and development in higher plants: The biochemistry of xylem and phloem production. In Biochemistry of cellular regulation (ed. M.E. Buckingham), pp. 145-178, CRC Press, Boca Raton, Florida.

Lamport, D.T.A. 1970. Cell wall metabolism. Annu. Rev. Plant Physiol. 21: 235-270.

Liang, X., M. Dron, J. Schmid, R.A. Dixon, and C.J. Lamb. 1989. Developmental and environmental regulation of a phenylalanine ammonia-lyase- $\beta$-glucuronidase gene fusion in transgenic tobacco plants. Proc. Natl. Acad. Sci. (in press).

Maniatis, T., E.F. Fritsch, and J. Sambrook, 1982. Molecular cloning: A laboratory manual. Cold Spring Harbor Laboratory, Cold Spring Harbor, New York.

Maxam, A.M. and W. Gilbert. 1980. Sequencing end-labeled DNA with base-specific chemical cleavages. Methods Enzymol. 65: 499-560.

Murray, M.G. and W.F. Thompson. 1980. Rapid isolation of high molecular weight DNA. Nucleic Acids Res. 8: 43214325.

Rigby, P.W.J., M. Dieckmann, C. Rhodes, and P. Berg. 1977. Labeling deoxyribonucleic acids to high specific activity in vitro by nick translation with DNA polymerase I. I. Mol. Biol. 113: 237-251.

Rocha-Sosa, M., W. Sonnewald, W. Frommer, M. Stratmann, J. Schell, and L. Willmitzer. 1989. Both developmental and environmental signals activate the promoter of a class I patatin gene. $E M B O$ /. 8: 23-30.

Sauer, N., D.R. Corbin, B. Keller, and C.J. Lamb. 1989. Cloning and characterization of a wound-specific hydroxyprolinerich glycoprotein in Phaseolus vulgaris. Plant, Cell, Environ., (in press).

Showalter, A.M., J.N. Bell, C.L. Cramer, J.A. Bailey, J.E. Varner, and C.J. Lamb. 1985. Accumulation of hydroxyproline-rich glycoprotein mRNAs in response to fungal elicitor and infection. Proc. Natl. Acad. Sci 82: 6551-6555.

Varner, J.E. and L.-S. Lin. 1989. Plant cell wall architecture. Cell 56: 231-239.

Von Heijne, G. 1988. Transcending the impenetrable: How proteins come to terms with membranes. Biochim. Biophys. Acta 947: 307-333.

Willmitzer, L. 1988. The use of transgenic plants to study plant gene expression. Trends Genet. 4: 13-18. 


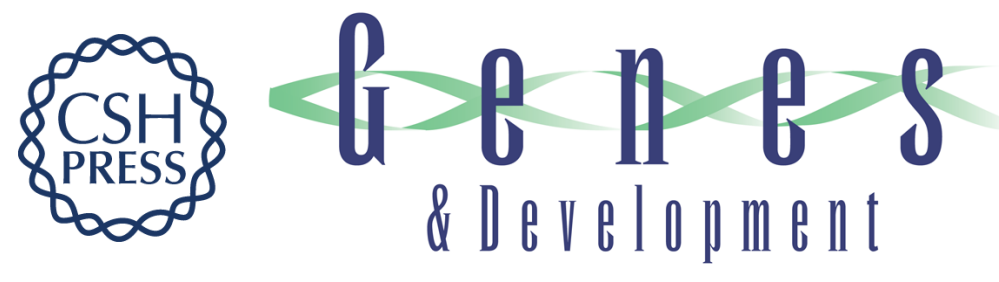

\section{Specific expression of a novel cell wall hydroxyproline-rich glycoprotein gene in lateral root initiation.}

B Keller and C J Lamb

Genes Dev. 1989, 3:

Access the most recent version at doi:10.1101/gad.3.10.1639

References This article cites 26 articles, 8 of which can be accessed free at:

http://genesdev.cshlp.org/content/3/10/1639.full.html\#ref-list-1

License

Email Alerting

Service

Receive free email alerts when new articles cite this article - sign up in the box at the top right corner of the article or click here.

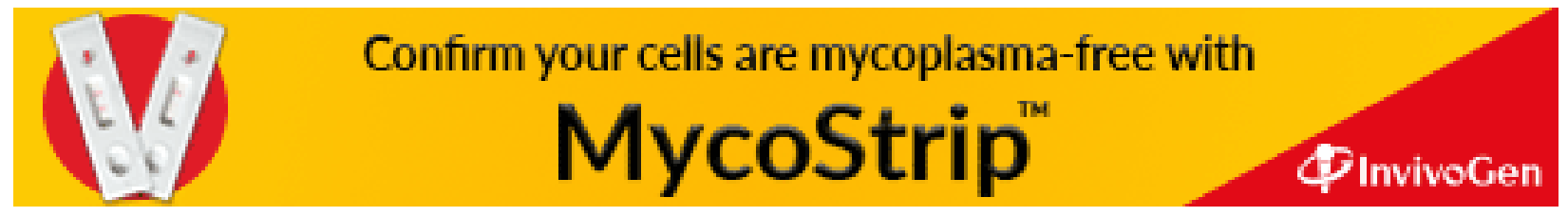

